\title{
Frequency-dependent Batesian mimicry
}

\section{Predators avoid look-alikes of venomous snakes only when the real thing is around.}

B atesian mimicry holds that palatable species look like dangerous species because both are then protected from predation $^{1-5}$. But this protection should break down where the dangerous model is absent, when predators would not be under selection to recognize the model or any other species resembling it as dangerous ${ }^{2,4,5}$. Here we provide experimental evidence to support this critical prediction of Batesian mimicry by demonstrating that predators avoid harmless look-alikes of venomous coral snakes only in areas that are inhabited by these deadly snakes.

Many coral snakes and non-venomous kingsnakes possess red, yellow (or white), and black ringed markings ${ }^{6}$, which predators avoid $^{7}$, though often without prior experience $^{8}$. To determine whether this avoidance depends on the model's presence in the vicinity, we constructed snake repli$\operatorname{cas}^{7}(1.5 \mathrm{~cm} \times 18 \mathrm{~cm}$ cylinders of precoloured, non-toxic plasticine threaded onto an S-shaped wire) with a tricolour ringed pattern, a striped pattern with identical colours and proportions as the ringed replicas, or a plain brown pattern.

Ringed replicas conformed to the local mimic: scarlet kingsnakes (Lampropeltis triangulum elapsoides), which resemble eastern coral snakes (Micrurus fulvius) ${ }^{9}$, or sonoran mountain kingsnakes (L. pyromelana), which resemble western coral snakes

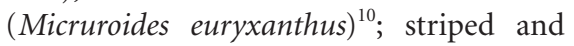
brown replicas served as controls. We arranged three different replicas (triplets) $2 \mathrm{~m}$ apart in natural habitat (each was used once only). At each site, 10 triplets were placed $75 \mathrm{~m}$ apart in a line. After collection, a person without knowledge of the replica's location scored attacks by noting any impressions corresponding to a predator ${ }^{7}$.

We tested whether predators avoid $L$. $t$. elapsoides only in areas inhabited by Micrurus by placing 10 triplets at eight sympatric sites (sites with mimic and model) and eight allopatric sites (sites with only the mimic) in North and South Carolina, USA (480 replicas; allopatric sites were more than $80 \mathrm{~km}$ outside Micrurus's range, sites were 16-420 km apart). After 4 weeks, $25(5.2 \%)$ replicas had been attacked by carnivores. The mean ( \pm s.e.m.) proportion of ringed replicas attacked was significantly greater in allopatry $(0.654 \pm 0.107)$ than in sympatry $(0.083 \pm 0.116 ; P=0.009$, 2-tailed Wilcoxon two-group test).

We next investigated whether predators avoid L. pyromelana only in sympatry with Micruroides by placing 10 triplets at 24 sites (720 replicas) along an elevational gradient
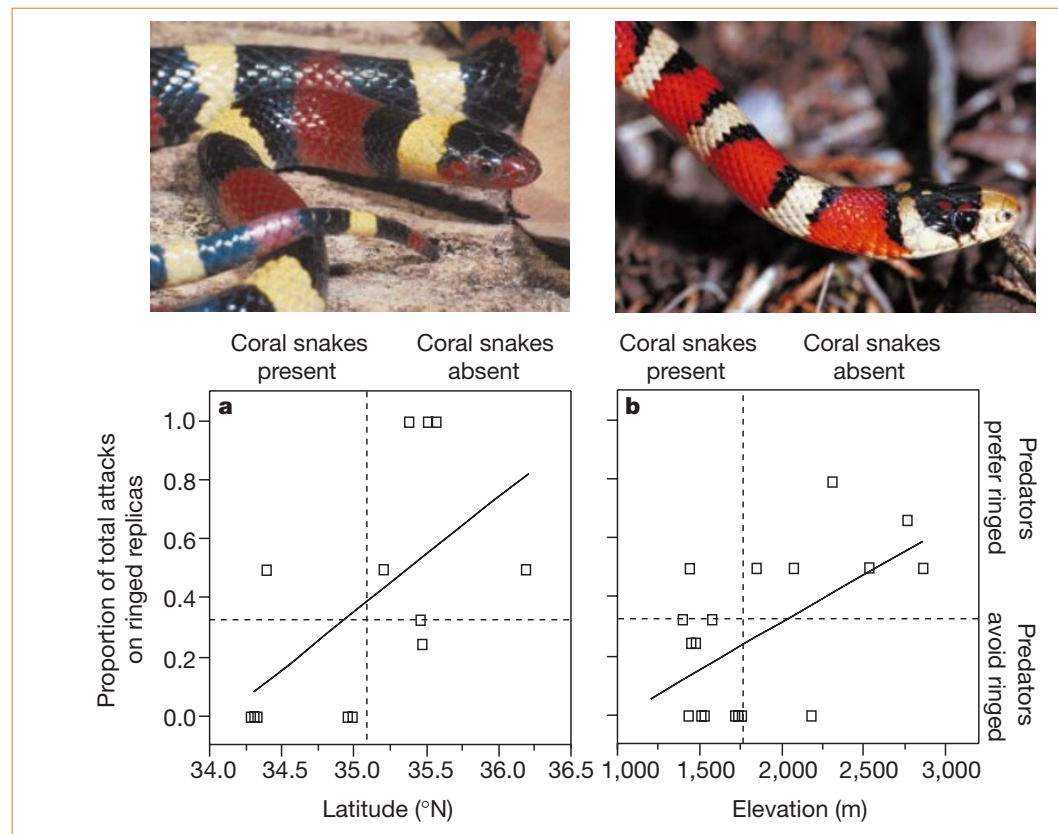

Figure 1 Frequency-dependent mimicry. The proportion of carnivore attacks on ringed replicas of scarlet kingsnakes (top left; a mimic of eastern coral snakes) and sonoran mountain kingsnakes (top right; a mimic of western coral snakes) increased with a, latitude $\left(y=-13.314+0.391 x, P<0.035, R^{2}=0.345\right)$ and $\mathbf{b}$, elevation $\left(y=-0.329+0.00032 x, P<0.014, R^{2}=0.310\right)$. Horizontal dashed line: proportion of attacks on ringed replicas expected under randomness. Vertical dashed line: maximum latitude and elevation for coral snakes in North Carolina and Arizona, respectively.

(1,204-2,866 m) near Portal, Arizona (Micruroides only occur at altitudes below 1,770 $\mathrm{m}$ (ref. 10); there were 14 sympatric and 10 allopatric sites $3-100 \mathrm{~km}$ apart). After 2 weeks, 49 (6.8\%) replicas had been attacked by carnivores.

The mean proportion of ringed replicas attacked was significantly greater in allopatry $(0.496 \pm 0.078)$ than in sympatry $(0.138 \pm 0.060 ; P=0.006)$. Moreover, in sympatry, the proportion of ringed replicas attacked (0.138) was significantly less than randomness $\quad(0.33 ; \quad P=0.010, \quad$ 2-tailed Wilcoxon signed-rank test). By contrast, attacks were random in allopatry $(P=0.188)$. Thus, predators avoid coral snake mimics only in sympatry with the model.

Coral snakes become increasingly rare with increasing latitude (Spearman $\rho=-0.57, \quad P=0.014)^{11} \quad$ and elevation $(\rho=-0.77, \quad P=0.026$; our unpublished results). Consequently, selection to avoid ringed patterns should weaken with increasing latitude and elevation. As expected, the proportion of ringed replicas attacked increased gradually with latitude and elevation (Fig. 1), suggesting that selection to avoid ringed patterns is indeed sensitive to the abundance of coral snakes.

Our results do not fully resolve why mimetic patterns occur where models are absent ${ }^{6,9-11}$. Possibly selection for mimicry in sympatry, coupled with gene flow between sympatric and allopatric populations $^{12}$, maintains mimetic patterns in both regions. Nevertheless, our results verify the critical prediction of Batesian mimicry and demonstrate that the benefits of mimicry depend on abundance of the model.

David W. Pfennig*, William R. Harcombe ${ }^{\star}$, Karin S. Pfennig $\dagger$

${ }^{*}$ Department of Biology, University of North

Carolina, Chapel Hill,

North Carolina 27599-3280, USA

e-mail:dpfennig@email.unc.edu

$\dagger$ Section of Integrative Biology, University of Texas, Austin, Texas 78712-1064, USA

1. Bates, H. W. Trans. Linn. Soc. Lond. 23, 495-566 (1862).

2. Wallace, A. R. Contributions to the Theory of Natural Selection (Macmillan, London, 1870).

3. Fisher, R. A. The Genetical Theory of Natural Selection. A Complete Variorum Edition (Oxford University Press, New York, 1999).

4. Waldbauer, G. P. Evol. Biol. 22, 227-259 (1988).

5. Maynard Smith, J. Evolutionary Genetics (Oxford University Press, Oxford, 1998).

6. Greene, H. W. \& McDiarmid, R. Y. Science 213, 1207-1212 (1981).

7. Brodie, E. D. Evolution 47, 227-235 (1993).

8. Smith, S. M. Science 187, 759-760 (1975).

9. Conant, R. \& Collins, J. T. A Field Guide to Reptiles and Amphibians of Eastern and Central North America (Houghton Mifflin, Boston, MA, 1998).

10. Stebbins, R. C. Western Reptiles and Amphibians (Houghton Mifflin, Boston, MA, 1985).

11. Palmer, W. M. \& Braswell, A. L. Reptiles of North Carolina (University of North Carolina Press, Chapel Hill, NC, 1995). 12. King, R. B. \& Lawson, R. BioScience 47, 279-286 (1997). 